OPEN ACCESS

Edited by:

Luis Cláudio Nascimento Da Silva CEUMA University, Brazil

Reviewed by:

Osmar Nascimento Silva, Universidade Católica Dom Bosco,

Brazil

Adrian Canizalez-Roman, Autonomous University of Sinaloa, Mexico

José Fernando Fierro,

University of Oviedo, Spain

*Correspondence:

Dee A. Carter

dee.carter@sydney.edu.au

Specialty section:

This article was submitted to

Antimicrobials, Resistance and

Chemotherapy,

a section of the journal

Frontiers in Microbiology

Received: 27 October 2016

Accepted: 03 January 2017

Published: 18 January 2017

Citation:

Fernandes KE and Carter DA (2017)

The Antifungal Activity of Lactoferrin and Its Derived Peptides: Mechanisms

of Action and Synergy with Drugs against Fungal Pathogens.

Front. Microbiol. 8:2.

doi: 10.3389/fmicb.2017.00002

\section{The Antifungal Activity of Lactoferrin and Its Derived Peptides: Mechanisms of Action and Synergy with Drugs against Fungal Pathogens}

\author{
Kenya E. Fernandes and Dee A. Carter* \\ School of Life and Environmental Sciences, University of Sydney, Sydney, NSW, Australia
}

Lactoferrin is a multifunctional iron-binding glycoprotein belonging to the transferrin family. It is found abundantly in milk and is present as a major protein in human exocrine secretions where it plays a role in the innate immune response. Various antifungal functions of lactoferrin have been reported including a wide spectrum of activity across yeasts and molds and synergy with other antifungal drugs in combination therapy, and various modes of action have been proposed. Bioactive peptides derived from lactoferrin can also exhibit strong antifungal activity, with some surpassing the potency of the whole protein. This paper reviews current knowledge of the spectrum of activity, proposed mechanisms of action, and capacity for synergy of lactoferrin and its peptides, including the three most studied derivatives: lactoferricin, lactoferrampin, and $L f(1-11)$, as well as some lactoferrin-derived variants and modified peptides.

Keywords: lactoferrin, lactoferricin, lactoferrampin, Lf(1-11), antimicrobial peptides, natural products, fungi, synergy

\section{INTRODUCTION}

The rising incidence of severe fungal infections, due largely to increased numbers of immunocompromised patients, has made the discovery of new compounds that have effective antifungal activity or that support the activity of currently used antifungal agents more important than ever. Natural products are a significant source of novel antimicrobial compounds, and an increasing number are being identified from mammalian sources including milk proteins. One example is the multifunctional iron-binding glycoprotein, lactoferrin (Lf), and its various derived peptides. This article will focus on the spectrum of antifungal activity shown by Lf when used alone and in combination with other antifungal drugs, and will review currently proposed mechanisms of antifungal action for $\mathrm{Lf}$ and its derived peptides.

First identified almost 80 years ago in bovine milk (Sorensen and Sorensen, 1939) and later isolated and purified from humans and cows in 1960 (Groves, 1960), Lf is produced by various mammals including pigs, goats, dogs, mice, and horses (Lönnerdal and Iyer, 1995; Garcia-Montoya et al., 2012). In humans, it is a major protein secreted by the epithelial cells into exocrine fluids such as tears, saliva, vaginal fluids, gastrointestinal fluids, bile, urine, and sweat (Masson et al., 1968; van der Strate et al., 2001; González-Chávez et al., 2009; Park et al., 2011) but is present at the highest concentrations in human colostrum and breast milk (Lönnerdal and Iyer, 1995). Lf is involved in various physiological functions including iron regulation and the innate immune response, and has been demonstrated to have anti-inflammatory, anti-oxidant, anti-allergic, and anti-cancer 
properties (Conneely, 2001; Kruzel et al., 2006; Actor et al., 2009; Iigo et al., 2009; Burrow et al., 2011; Ogasawara et al., 2014) in addition to antimicrobial activity against a wide range of fungal, bacterial, viral, and parasitic pathogens (Jenssen and Hancock, 2009; Leboffe et al., 2009; Berlutti et al., 2011; Giansanti et al., 2013). The ability to bind and sequester iron is an important component of the antimicrobial activity of Lf (Jenssen and Hancock, 2009).

In addition to being an active intact protein, $\mathrm{Lf}$ is a rich source of antimicrobial peptides that are cleaved from the polypeptide chain by various proteolytic enzymes. As many of these enzymes are present in various body sites in humans, it is expected that a number of the cleaved peptides contribute to the normal functions of Lf in the body (Sinha et al., 2013). An increasing number of Lf-derived peptides are also being generated and modified by chemical synthesis (van der Kraan et al., 2005a). Many Lf peptides exhibit a broad spectrum of antimicrobial activity, have various different structural elements and modes of action, and appear to perform numerous functions including modulation of the inflammatory response, and stimulation of apoptosis (Farnaud et al., 2004; Sánchez-Gómez et al., 2008; van der Does et al., 2012).

\section{STRUCTURE AND ANTIFUNGAL ACTIVITY OF WHOLE LACTOFERRIN}

The structure of Lf consists of a single polypeptide chain containing $\sim 700$ amino acids folded into two globular lobes. These lobes are highly homologous to each other and are connected by an $\alpha$-helical residue providing flexibility to the Lf molecule. Each lobe consists of two domains forming a single iron binding site, allowing each Lf molecule to strongly bind two ferric ions (Anderson et al., 1989). The open, iron-free form of Lf is known as apo-Lf while the closed, iron-rich form is holoLf, which differs in tertiary structure and is more resistant to proteolysis than apo-Lf (Jameson et al., 1998). In addition to binding $\mathrm{Fe}^{3+}$, Lf has also been observed to bind a range of other compounds including lipopolysaccharides, heparin, DNA, and metal ions including $\mathrm{Cu}^{2+}, \mathrm{Zn}^{2+}$, and $\mathrm{Mn}^{2+}$ (Baker, 1994).

Lf is most commonly purified from human (hLf) or bovine (bLf) milk but it has also been obtained from the milk and colostrum of several other mammals. Recombinant Lf (rLf) is increasingly being generated from microbial expression systems and through transgenic plants and animals (Lönnerdal and Iyer, 1995). Lf molecules from across species are highly homologous but have varying antifungal activity owing to small differences in structure. Furthermore, the level of activity of Lf with similar purities can vary substantially between different producers, ranging from reasonably active to inactive in the same test organism. bLf in particular has well-documented activity against a range of human and plant fungal pathogens including yeasts and molds (Table 1). Most widely studied is its activity on members of the Candida species, with Candida tropicalis, Candida krusei, and Candida albicans exhibiting the highest level of susceptibility while Candida glabrata has the lowest (Nikawa et al., 1993; Xu et al., 1998).
Early studies with Candida species attributed the antifungal effect of Lf to its ability to sequester iron resulting in a fungistatic effect (Kirkpatrick et al., 1971), and inhibition of growth of Candida and Cryptococcus can be rescued by the addition of iron (Al-Sheikh, 2009; Lai et al., 2016). In Aspergillus fumigatus, the sequestration of $\mathrm{Fe}^{3+}$ by apo-Lf was shown to be important for host defense (Zarember et al., 2007) indicating that iron sequestration can play a role in the antifungal action of Lf in vivo. More recent studies now suggest that the main antifungal mechanism of Lf is iron-independent and occurs through a direct interaction of Lf with the fungal cell surface, leading to cell membrane damage and leakage. Supernatant protein assays and propidium iodide staining have shown that Lf alters cell surface permeability in C. albicans, C. krusei, and Cryptococcus neoformans, leading to cell death (Nikawa et al., 1993; Wakabayashi et al., 1996; Kondori et al., 2011). Alterations to the cell surface itself including protein leakage, the formation of surface blebs, swelling, and cell collapse have been seen in Candida isolates through scanning electron microscopy (Nikawa et al., 1993; Wakabayashi et al., 1996; Xu et al., 1998; van der Kraan et al., 2005b).

The cellular release of potassium ions, cytosolic acidification, changes in membrane potential, intracellular ROS accumulation, and chromatin condensation have all been detected in C. albicans following treatment with Lf indicating the induction of an apoptotic phenotype (Viejo-Díaz et al., 2004; Andres et al., 2008). The details by which Lf induces apoptosis-like processes in fungi remain largely unclear, however, recent studies have examined this mechanism in significant yeast species. In Saccharomyces cerevisiae, it was shown that hLf induces cell death in a mitochondrial and caspase-dependent way that is characterized by caspase activation, ROS accumulation and cytochrome $\mathrm{c}$ release (Acosta-Zaldivar et al., 2016). Work by the same group in C. albicans indicated that the proton-translocating ATPase Pmalp, which is a primary contributor to $\mathrm{pH}$ regulation in yeasts, was the target of hLf, inducing lethal mitochondrial dysfunction (Andres et al., 2016).

The combined use of Lf with other antifungal drugs has been increasingly studied in recent years. When combined with fluconazole, various sources of Lf have been observed to significantly enhance inhibitory activity and decrease the minimum inhibitory concentration (MIC) for several Candida species, including wild type and clinical strains, and ergosterol biosynthesis and azole-resistant mutants (Wakabayashi et al., 1998; Kuipers et al., 1999; Naidu et al., 2004; Venkatesh and Rong, 2008; Kobayashi et al., 2011). The mechanism of synergy between Lf and fluconazole is not yet well-understood and does not appear to result from an increased intracellular uptake of fluconazole, as the intracellular concentration of radiolabelled fluconazole was not affected by the addition of bLf (Kobayashi et al., 2011).

Several other azole drugs, including itraconazole, clotrimazole, and ketoconazole, as well as 5-fluorocytosine have been demonstrated to function synergistically with Lf in C. albicans (Wakabayashi et al., 1996; Kuipers et al., 1999). The polyene drugs amphotericin $\mathrm{B}$ and nystatin exhibited no interactions with bLf when tested in Candida species (Wakabayashi et al., 1996) although amphotericin B and 
TABLE 1 | Antifungal spectrum of activity of Lf and derived peptides.

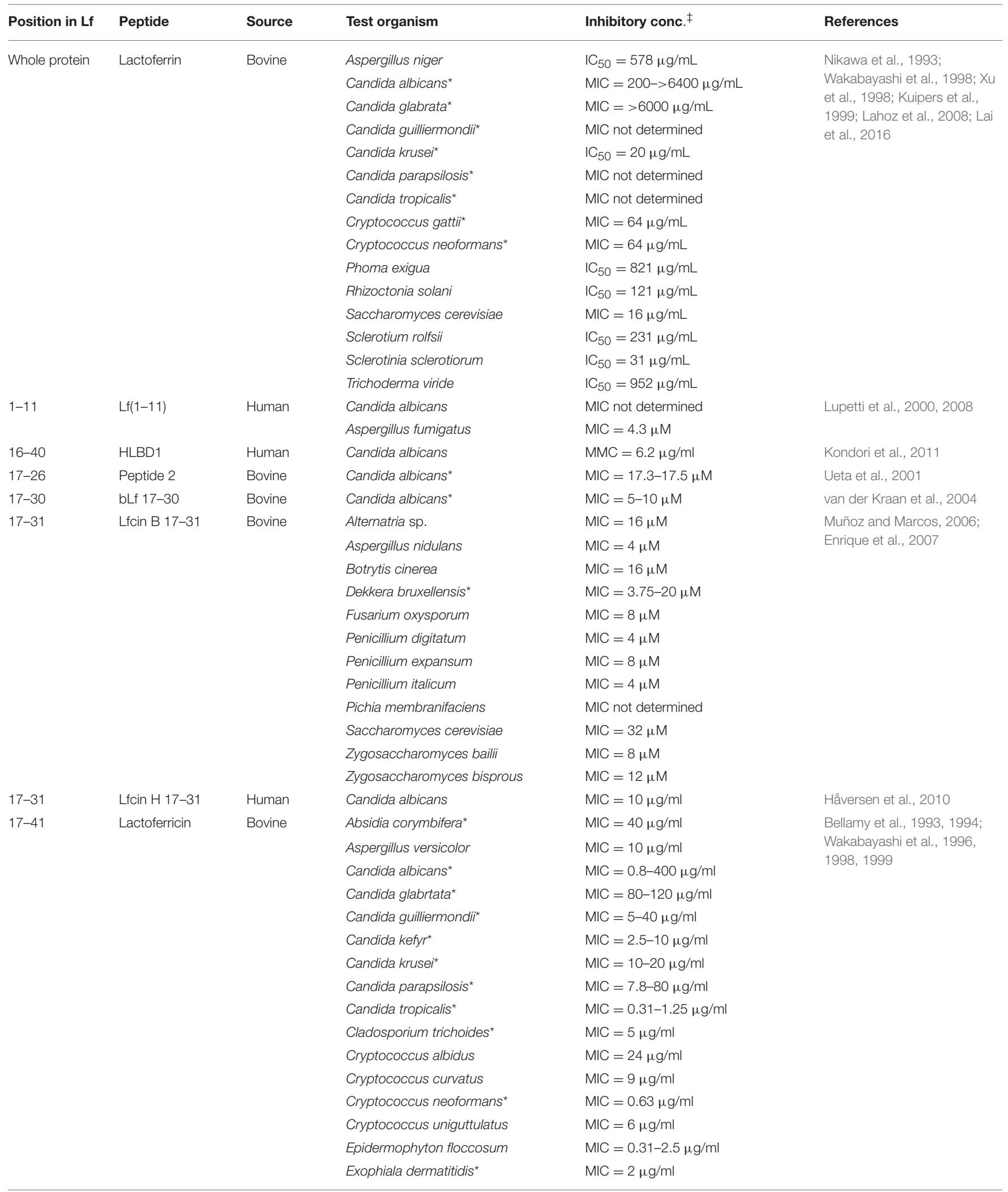


TABLE 1 | Continued

\begin{tabular}{|c|c|c|c|c|c|}
\hline Position in Lf & Peptide & Source & Test organism & Inhibitory conc. ${ }^{\ddagger}$ & References \\
\hline & & & Fusarium moniliforme ${ }^{\star}$ & $\mathrm{MIC}=2.5-5 \mu \mathrm{g} / \mathrm{ml}$ & \\
\hline & & & Microsporum gypseum & $\mathrm{MIC}=20-40 \mu \mathrm{g} / \mathrm{ml}$ & \\
\hline & & & Nannizia gypsea & $\mathrm{MIC}=30 \mu \mathrm{g} / \mathrm{ml}$ & \\
\hline & & & Paracoccidioides brasiliensis ${ }^{*}$ & $\mathrm{MIC}=0.63-1.25 \mu \mathrm{g} / \mathrm{ml}$ & \\
\hline & & & Penicillium pinophilum & $\mathrm{MIC}=45 \mu \mathrm{g} / \mathrm{ml}$ & \\
\hline & & & Penicillium vermiculatum & $\mathrm{MIC}=45 \mu \mathrm{g} / \mathrm{ml}$ & \\
\hline & & & Phialophora verrucosa* & $\mathrm{MIC}=5-10 \mu \mathrm{g} / \mathrm{ml}$ & \\
\hline & & & Saccharomyces cerevisiae & $\mathrm{MIC}=0.63 \mu \mathrm{g} / \mathrm{ml}$ & \\
\hline & & & Trichophyton violaceum ${ }^{\star}$ & $\mathrm{MIC}=40 \mu \mathrm{g} / \mathrm{ml}$ & \\
\hline & & & Trichosporon cutaneum ${ }^{\star}$ & $\mathrm{MIC}=1.25-18 \mu \mathrm{g} / \mathrm{ml}$ & \\
\hline $18-31$ & Lfcin 18-31 & Human & Candida albicans & $\mathrm{MIC}=10 \mu \mathrm{g} / \mathrm{ml}$ & Håversen et al., 2010 \\
\hline $18-37$ & Lfcin B-20 & Bovine & Candida albicans & $\mathrm{MIC}=8 \mu \mathrm{g} / \mathrm{ml}$ & Chen et al., 2006 \\
\hline $18-37$ & Lfcin P-20 & Porcine & Candida albicans & $\mathrm{MIC}=32 \mu \mathrm{g} / \mathrm{ml}$ & Chen et al., 2006 \\
\hline \multirow[t]{5}{*}{$18-40$} & Lfpep & Human & Candida albicans & $\mathrm{MIC}=18.7 \mu \mathrm{M}$ & Viejo-Diaz et al., 2005 \\
\hline & & & Candida glabrata & $\mathrm{MIC}=9.3 \mu \mathrm{M}$ & \\
\hline & & & Candida guilliermondii & $\mathrm{MIC}=9.3 \mu \mathrm{M}$ & \\
\hline & & & Candida krusei & $\mathrm{MIC}=4.7 \mu \mathrm{M}$ & \\
\hline & & & Candida parapsilosis & $\mathrm{MIC}=9.3 \mu \mathrm{M}$ & \\
\hline & & & Pichia membranifaciens & MIC not determined & \\
\hline & & & Zygosaccharomyces bailii & MIC not determined & \\
\hline & & & Zygosaccharomyces bisporus & MIC not determined & \\
\hline & & & Cryptococcus albidus & MIC not determined & \\
\hline & & & Penicillium digitatum & $\mathrm{MIC}=8 \mu \mathrm{M}$ & \\
\hline & & & Penicillium italicum & $\mathrm{MIC}=8 \mu \mathrm{M}$ & \\
\hline & & & Penicillium expansum & $\mathrm{MIC}=16 \mu \mathrm{M}$ & \\
\hline & & & Penicillium sp. & $\mathrm{MIC}=32 \mu \mathrm{M}$ & \\
\hline & & & Aspergillus nidulans & $\mathrm{MIC}=8 \mu \mathrm{M}$ & \\
\hline & & & Botrytis cinerea & $\mathrm{MIC}=16 \mu \mathrm{M}$ & \\
\hline & & & Fusarium oxysporum & $\mathrm{MIC}=16 \mu \mathrm{M}$ & \\
\hline \multirow[t]{2}{*}{$20-28$} & Lfcin B-9 & Bovine & Candida albicans ${ }^{*}$ & $\mathrm{MIC}=25-32 \mu \mathrm{g} / \mathrm{ul}$ & Wakabayashi et al., 1999; \\
\hline & & & Trichophyton mentagrophytes & $\mathrm{MIC}=6 \mu \mathrm{g} / \mathrm{ul}$ & Chen et al., 2006 \\
\hline $20-28$ & Lfcin P-9 & Porcine & Candida albicans & $\mathrm{MIC}=512 \mu \mathrm{g} / \mathrm{ml}$ & Chen et al., 2006 \\
\hline \multirow[t]{3}{*}{$20-31$} & HL10 & Human & Candida albicans ${ }^{\star}$ & $\mathrm{MMC}=100-200 \mu \mathrm{g} / \mathrm{ml}$ & \multirow{3}{*}{$\begin{array}{l}\text { Håversen et al., 2010; } \\
\text { Kondori et al., } 2011\end{array}$} \\
\hline & & & Candida parapsilosis* & $\mathrm{MMC}=100-200 \mu \mathrm{g} / \mathrm{ml}$ & \\
\hline & & & Candida kefyr & $\mathrm{MMC}=100 \mu \mathrm{g} / \mathrm{ml}$ & \\
\hline
\end{tabular}


TABLE 1 | Continued

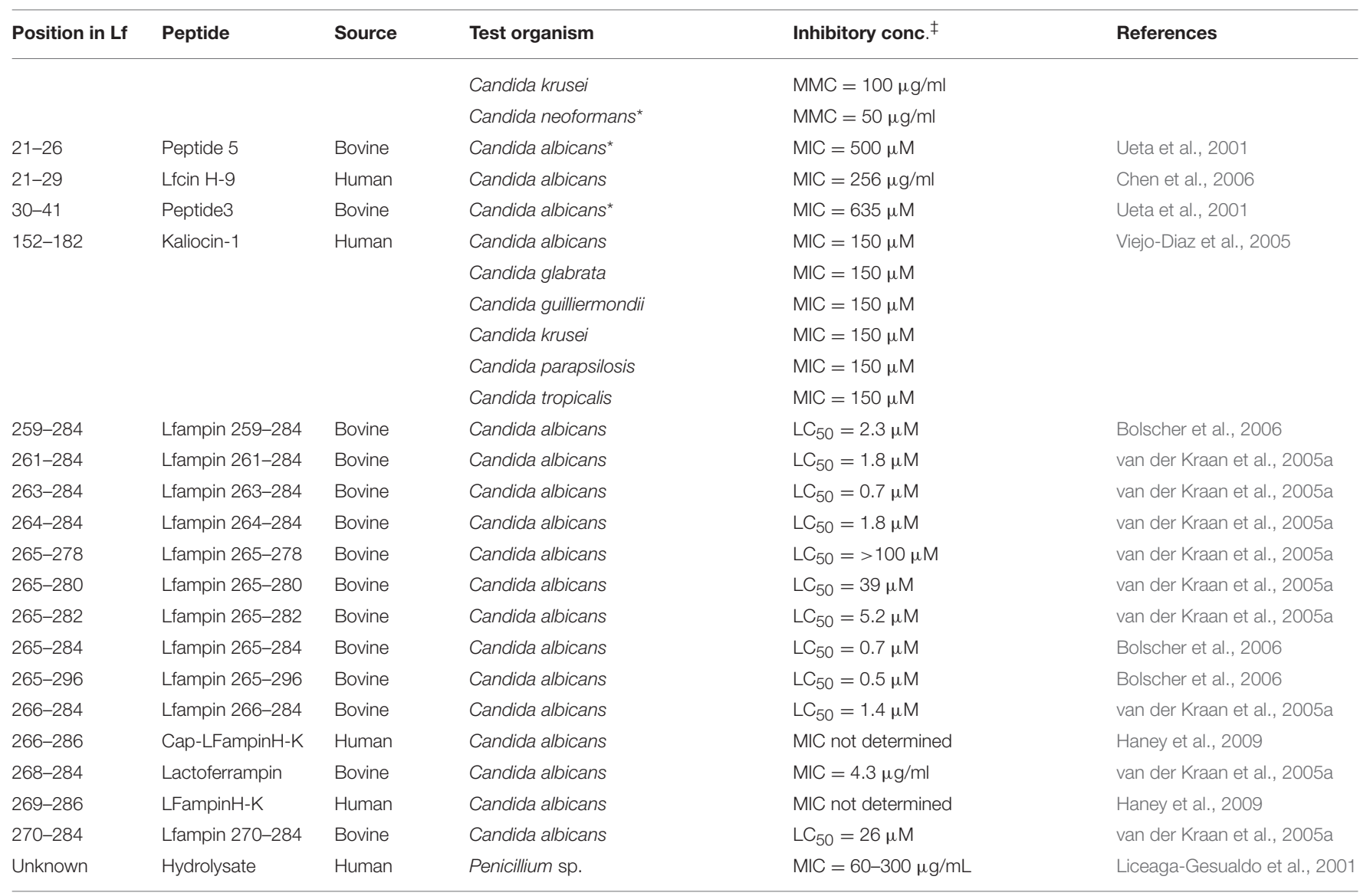

${ }^{*}$ Indicates multiple strains were tested within species. ${ }^{\ddagger} / C_{50}$, Inhibitory Concentration (50\% Inhibition); LC 50 , Lethal Concentration (50\% Mortality); MIC, Minimum Inhibitory Concentration; MMC, Minimum Microbiocidal Concentration. As different studies have used varying methods and sources of lactoferrin to determine inhibitory concentrations, these values may not be comparable between studies.

bLf have been found to act synergistically in Cryptococcus neoformans, Cryptococcus gattii, and S. cerevisiae. The addition of exogenous iron did not rescue growth of Cryptococcus treated with amphotericin B and bLf, indicating that the mechanism of synergy is not solely due to iron chelation (Lai et al., 2016).

\section{STRUCTURE AND ANTIFUNGAL ACTIVITY OF LACTOFERRICIN-THE MAJOR PEPTIDE DERIVED FROM LACTOFERRIN}

Lactoferricin (Lfcin) is found in the human gut as a natural breakdown product and was first generated by Bellamy et al. (1992) through pepsin hydrolysis of intact Lf. Bovine lactoferricin (bLfcin), comprising residues 17-41 from the $\mathrm{N}$-terminal region of Lf, is simpler in structure but much more potent than human lactoferricin (hLfcin), which comprises residues 1-47. Both Lfcins possess an 18-residue loop region with a disulphide bridge and many positively charged and hydrophobic residues (Gifford et al., 2005).

The three dimensional structures of hLfcin and bLfcin differ from each other and from the homologous regions of the intact Lf protein, and it is thought these differences determine their different antifungal efficacies. While bLfcin forms a $\beta$ sheet confirmation in solution that contains a group of aligned hydrophobic residues well-suited to interactions with biological membranes, hLfcin forms a coiled structure in solution lacking the aligned residues and thus having weaker interactions with the target cell (Farnaud et al., 2004; Hunter et al., 2005; Alexander et al., 2012). Lfcin shows strongly enhanced antimicrobial activity compared to Lf and the antifungal efficacy of bLfcin, in particular, has been observed across a large range of various types of fungi (Table 1).

The primary antifungal mechanism of action of Lfcin appears to be through direct interaction with the fungal surface and disruption of the fungal membrane (Bellamy et al., 1993). Using confocal scanning laser microscopy, it was observed that bLfcin molecules were internalized by $C$. albicans cells within minutes (van der Kraan et al., 2005b) and that treatment with Lfcin resulted in dissipation of the proton gradient across the cell membrane (Gifford et al., 2005). In $C$. albicans and in the dermatophyte Trichophyton mentagrophytes, changes in ultrastructural features and an aggregation of cytoplasmic materials observed following treatment with Lfcin 
were traced to stimulation of ATP synthesis and extracellular secretion, resulting in pore formation in the plasma membrane (Bellamy et al., 1994; Ueta et al., 2001). Lfcin has also been shown to upregulate host defense via the induction of reactive oxygen species that stimulate the fungicidal activities of polymorphonuclear leukocytes (Kullberg et al., 1999). This ability to mount a combined assault on microbial pathogens is a common feature of natural host-derived products, most likely resulting from evolutionary pressures to maintain efficacy and prevent pathogens from developing resistance (Xu et al., 2009; Carter et al., 2016).

Synergy between bLfcin and azole antifungal drugs has been observed in C. albicans. In azole-resistant strains, the addition of low levels of bLfcin greatly increased inhibition by fluconazole and itraconazole and was seen to inhibit the growth of fungal hyphae (Wakabayashi et al., 1998). bLfcin has also been observed to function synergistically with clotrimazole and ketoconazole and it significantly reduced the formation of biofilms when used in combination with voriconazole and amphotericin B (Wakabayashi et al., 1996). The mechanistic basis of these synergistic actions remains unknown.

\section{ANTIFUNGAL ACTIVITY OF OTHER LACTOFERRIN-DERIVED PEPTIDES}

\section{Lactoferrampin}

Lactoferrampin (Lfampin), comprising residues 268-284 in the $\mathrm{N} 1$ domain of Lf, is located in close proximity to Lfcin in the tertiary structure of Lf. Identified as a molecule of interest due to its net positive charge and possession of a hydrophobic domain, Lfampin is thought to play a role in membranemediated activities of Lf (van der Kraan et al., 2004). Lfampin has demonstrated antifungal efficacy against $C$. albicans and is known to be more potent than Lf but has not yet been tested with a wide range of fungal organisms (Table 1). Similarly, whether Lfampin acts synergistically with antifungal drugs has not yet been determined.

Like Lfcin, the mechanism of action of Lfampin is by binding to and disrupting the cell membrane, and it was similarly observed to be internalized within a few minutes by C. albicans, resulting in membrane permeabilisation and the formation of vesicle-like structures (van der Kraan et al., 2005b). However, Lfampin differs greatly from Lfcin in amino acid composition, structure and orientation. In solution, the first 11 residues of bovine lactoferrampin (bLfampin) form an $\alpha$-helical structure (Haney et al., 2007). A tryptophan residue in the N-terminal region has been shown to interact with model membranes and is contained in all varieties of Lfampin from different sources involved in membrane insertion indicating that it is responsible for this function (Haney et al., 2007; Sinha et al., 2013).

\section{Lf(1-11)}

The $\operatorname{Lf}(1-11)$ peptide comprises the first 11 amino acid residues of the $\mathrm{N}$-terminal region of Lf and exhibits antifungal activity against C. albicans and A. fumigatus (Table 1; Lupetti et al., 2000). The mechanism of action of $\operatorname{Lf}(1-11)$ also appears to rely on interactions with the fungal membrane, with important structural features including its highly cationic nature and the presence of hydrophobic valine (V6) and tryptophan (W8) residues (Bruni et al., 2016). Lupetti et al. (2000) demonstrated through residue substitution that the first two arginines at the N-terminus (R2, R3) are also necessary for the antifungal action of $\mathrm{hLf}(1-11)$ in C. albicans. $\mathrm{hLf}(1-11)$ appears to have immunomodulatory properties during $C$. albicans infection where it directs the differentiation of monocytes into dendritic cells that enhance the polarization of a Th17 response, which is an important component of the host defense against fungi (van der Does et al., 2012).

When combined with fluconazole, a synergistic antifungal effect has been seen across various Candida species including $C$. glabrata, C. krusei, C. parapsilosis, C. tropicalis, and fluconazoleresistant strains of $C$. albicans. At sub-inhibitory concentrations, these yeasts were seen to be killed when preincubated with hLf(111) before introducing fluconazole but not when fluconazole was introduced first, indicating that $\mathrm{hLf}(1-11)$ is responsible for initiating candidacidal activity while fluconazole acts synergistically during a later stage (Lupetti et al., 2003).

\section{Synthetic Peptides Based on Lactoferrin}

A wide variety of other derivatives of varying size and location have been generated from the whole Lf protein (Table 1). A number of these peptides were created in an attempt to facilitate the discovery of other antimicrobial sequences composed of short core residues within Lf. As an example of this, Chen et al. (2006) created and tested a range of short synthetic derivatives of human, bovine, and porcine Lfcins in an attempt to discover other antimicrobial sequences comprising core residues within Lf. This enabled them to find the antimicrobial domain in Lfcin of porcine origin, and to compare its potency to Lfcins of human and bovine origin.

Lf derivatives have also been designed to help clarify the relationship between structure and function of particular Lfderived peptides. In one study, by testing a collection of peptides obtained by extending and/or truncating the C- or $\mathrm{N}$ - terminal ends of Lfampin, it was demonstrated that the highest level of antimicrobial activity corresponded with strongest membrane interactions and greatest ability to form an $\alpha$-helix (Adão et al., 2011). In another study, a significant increase in candidacidal activity was seen in an extended form of Lfampin due to an increased positive charge near the C-terminal end (Haney et al., 2009). These studies demonstrate that there is capacity to optimize the activity of Lf-derived molecules by careful consideration of their sequence and structural properties.

\section{Modified and Lactoferrin-Like Peptides}

In recent years, an increasing number of studies have taken the path of modifying the original amino acid sequence of Lf peptides in order to develop more potent antifungal activity than in the parent peptides (Table 2). Various strategies designed to alter properties related to antifungal activity have been employed in the construction of these novel peptides such as modifying the length, net charge, and hydrophobicity of the peptide. 


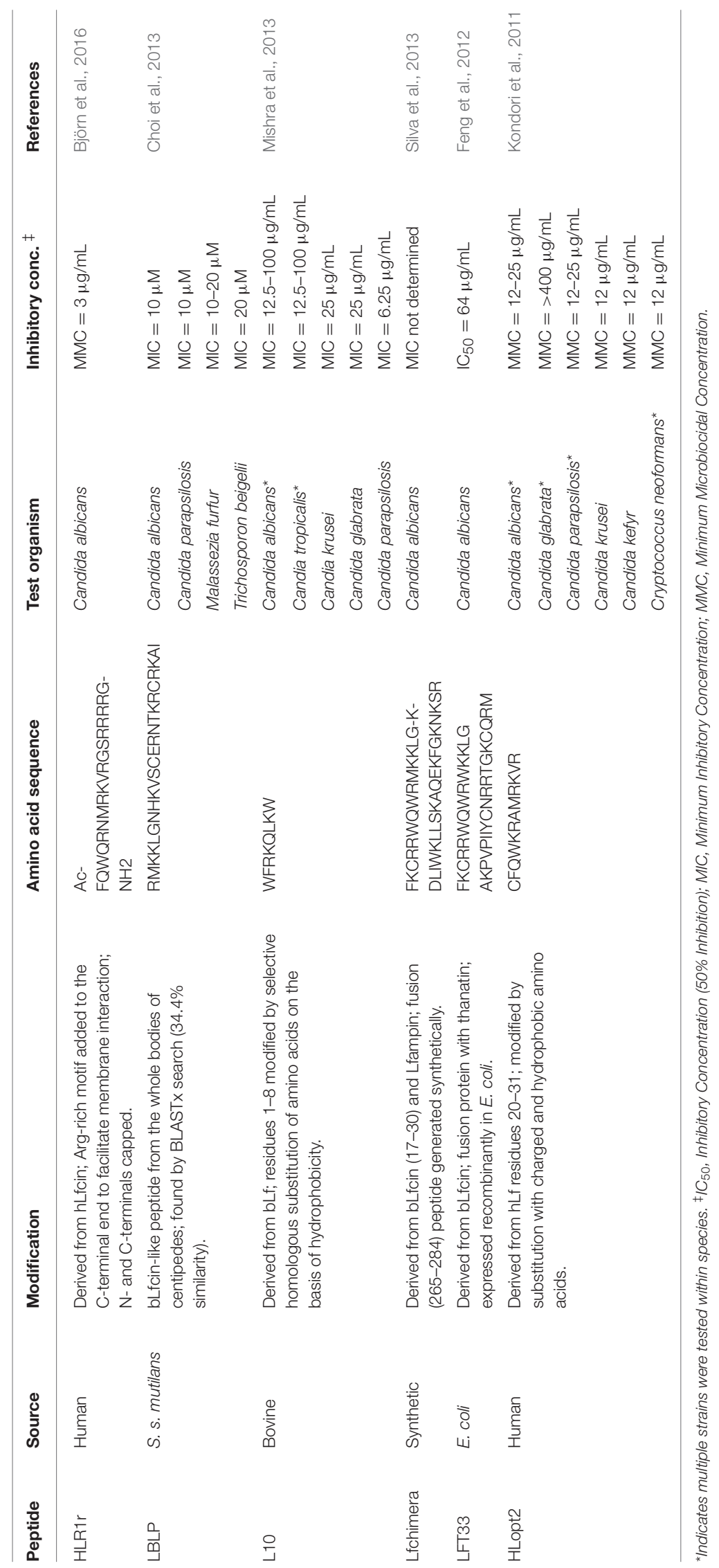


By the selective substitution of amino acids based on hydrophobicity in groups of residues derived from the $\mathrm{N}$ terminal end of hLf, Kondori et al. (2011) and Mishra et al. (2013) created HLopt2 and L10, respectively. Björn et al. (2016) subsequently developed HLR1r from hLfcin by the addition of an Arg-rich motif designed to facilitate membrane interactions, together with capping of the $\mathrm{N}$ - and C- terminals to make them neutral. These three peptides demonstrated potent antifungal action against Candida species that was substantially greater than that of the corresponding residues from the native Lf peptide. Taking another approach, fusion peptides have been generated synthetically from the combination of multiple bioactive peptides: Lfchimera, a fusion of bLfcin and Lfampin, and LFT33, a fusion of bLfcin and the insect-derived antimicrobial peptide thanatin (Feng et al., 2012; Silva et al., 2013).

In addition to modifications of the natural peptide, the sequence of Lf has been used to search for other naturally occurring peptides with high homology in order to facilitate discovery of novel potential antifungals. The utility of this approach was demonstrated by the discovery of LBLP, a peptide with $34.4 \%$ similarity to bLfcin and produced from the bodies of centipedes, which was found to have strong antifungal activity against strains of Candida, Malassezia, and Trichosporon (Choi et al., 2013).

\section{SUMMARY AND CONCLUSIONS}

Lf and its major naturally cleaved peptide, Lfcin, have proven broad-spectrum antifungal action, with Lfcin exhibiting greater potency than the intact protein. The less well-characterized peptides including Lfampin and $\operatorname{Lf}(1-11)$ have also been seen to

\section{REFERENCES}

Acosta-Zaldivar, M., Andres, M. T., Rego, A., Pereira, C. S., Fierro, J. F., and CorteReal, M. (2016). Human lactoferrin triggers a mitochondrial- and caspasedependent regulated cell death in Saccharomyces cerevisiae. Apoptosis 21, 163-173. doi: 10.1007/s10495-015-1199-9

Actor, J. K., Hwang, S. A., and Kruzel, M. L. (2009). Lactoferrin as a natural immune modulator. Curr. Pharm. Des. 15, 1956-1973. doi: 10.2174/138161209788453202

Adão, R., Nazmi, K., Bolscher, J. G., and Bastos, M. (2011). C- and Ntruncated antimicrobial peptides from LFampin 265-284: biophysical versus microbiology results. J. Pharm. Bioallied Sci. 3, 60-69. doi: 10.4103/0975-7406.76467

Alexander, D. B., Iigo, M., Yamauchi, K., Suzui, M., and Tsuda, H. (2012). Lactoferrin: an alternative view of its role in human biological fluids. Biochem. Cell Biol. 90, 279-306. doi: 10.1139/o2012-013

Al-Sheikh, H. (2009). Effect of lactoferrin and iron on the growth of human pathogenic Candida species. Pak. J. Biol. Sci. 12, 91-94. doi: $10.3923 /$ pjbs.2009.91.94

Anderson, B. F., Baker, H. M., Norris, G. E., Rice, D. W., and Baker, E. N. (1989). Structure of human lactoferrin: crystallographic structure analysis and refinement at $2.8 \mathrm{~A}$ resolution. J. Mol. Biol. 209, 711-734. doi: 10.1016/0022-2836(89)90602-5

Andres, M. T., Acosta-Zaldivar, M., and Fierro, J. F. (2016). Antifungal mechanism of action of lactoferrin: identification of H+-ATPase (P3A-type) as a new apoptotic-cell membrane receptor. Antimicrob. Agents Chemother. 60, 4206-4216. doi: 10.1128/AAC.03130-15 possess increased antifungal potency in Candida species but have not been tested extensively beyond this. Lf and Lfcin function synergistically primarily with azole antifungal drugs, however, knowledge of the spectrum and mechanism of these synergistic interactions is lacking, and synergy is largely unexplored for the other Lf-derived peptides.

Mechanistically, Lf and its peptides have been shown to function primarily through membrane destabilization, with immunomodulation and iron sequestration playing secondary roles. Although many aspects of Lf-derived peptides are quite conserved, differences in amino acid composition and tertiary structure contribute to their different functional properties. Novel alternative peptides that have been generated or modified from the original sequence of Lf provide insight into the relationship between structure and function. Lf and its derived peptides have great potential as leads for future antifungal drug development, however, considerable research is still required to understand the antifungal actions of these molecules as well as their potential to support current antifungals.

\section{AUTHOR CONTRIBUTIONS}

This article was written by $\mathrm{KF}$ and was reviewed and edited by DC.

\section{FUNDING}

Work on Lf in the Carter Lab has been supported by the Australian National Health and Medical Research Council (Grant Number APP1021267). KF is financially supported by an Australian Postgraduate Award.

Andres, M. T., Viejo-Diaz, M., and Fierro, J. F. (2008). Human lactoferrin induces apoptosis-like cell death in Candida albicans: critical role of $\mathrm{K}+-$ channel-mediated K+ efflux. Antimicrob. Agents Chemother. 52, 4081-4088. doi: 10.1128/AAC.01597-07

Baker, E. N. (1994). Structure and reactivity of transferrins. Adv. Inorg. Chem. 41, 389-463. doi: 10.1016/S0898-8838(08)60176-2

Bellamy, W., Takase, M., Wakabayashi, H., Kawase, K., and Tomita, M. (1992). Antibacterial spectrum of lactoferricin B, a potent bactericidal peptide derived from the N-terminal region of bovine lactoferrin. J. Appl. Bacteriol. 73, 472-479. doi: 10.1111/j.1365-2672.1992.tb05007.x

Bellamy, W., Wakabayashi, H., Takase, M., Kawase, K., Shimamura, S., and Tomita, M. (1993). Killing of Candida albicans by lactoferricin B, a potent antimicrobial peptide derived from the N-terminal region of bovine lactoferrin. Med. Microbiol. Immunol. 182, 97-105. doi: 10.1007/BF001 89377

Bellamy, W., Yamauchi, K., Wakabayashi, H., Takase, M., Takakura, N., Shimamura, S., et al. (1994). Antifungal properties of lactoferricin B, a peptide derived from the N-terminal region of bovine lactoferrin. Lett. Appl. Microbiol. 18, 230-233. doi: 10.1111/j.1472-765X.1994.tb00854.x

Berlutti, F., Pantanella, F., Natalizi, T., Frioni, A., Paesano, R., Polimeni, A., et al. (2011). Antiviral properties of lactoferrin - a natural immunity molecule. Molecules 16, 6992-7018. doi: 10.3390/molecules16086992

Björn, C., Mahlapuu, M., Mattsby-Baltzer, I., and Håkansson, J. (2016). Antiinfective efficacy of the lactoferrin-derived antimicrobial peptide HLR1r. Peptides 81, 21-28. doi: 10.1016/j.peptides.2016.04.005

Bolscher, J. G., van der Kraan, M. I., Nazmi, K., Kalay, H., Grun, C. H., Van't Hof, W., et al. (2006). A one-enzyme strategy to release an antimicrobial 
peptide from the LFampin-domain of bovine lactoferrin. Peptides 27, 1-9. doi: $10.1016 /$ j.peptides.2005.06.012

Bruni, N., Capucchio, M. T., Biasibetti, E., Pessione, E., Cirrincione, S., Giraudo, L., et al. (2016). Antimicrobial activity of lactoferrin-related peptides and applications in human and veterinary medicine. Molecules 21, 752. doi: $10.3390 /$ molecules 21060752

Burrow, H., Kanwar, R. K., and Kanwar, J. R. (2011). Antioxidant enzyme activites of iron-saturated bovine lactoferrin (Fe-blf) in human gut epithelial cells under oxidative stress. Med. Chem. 7, 224-230. doi: 10.2174/157340611795564286

Carter, D. A., Blair, S. E., Cokcetin, N. N., Bouzo, D., Brooks, P., Schothauer, R., et al. (2016). Therapeutic manuka honey: no longer so alternative. Front. Microbiol. 7:569. doi: 10.3389/fmicb.2016.00569

Chen, H. L., Yen, C. C., Lu, C. Y., Yu, C. H., and Chen, C. M. (2006). Synthetic porcine lactoferricin with a 20 -residue peptide exhibits antimicrobial activity against Escherichia coli, Staphylococcus aureus and Candida albicans. J. Agric. Food Chem. 54, 3277-3282. doi: 10.1021/jf053031s

Choi, H., Hwang, J. S., and Lee, D. G. (2013). Antifungal effect and poreforming action of lactoferricin B like peptide derived from centipede Scolopendra subspinipes mutilans. Biochim. Biophys. Acta 1828, 2745-2750. doi: 10.1016/j.bbamem.2013.07.021

Conneely, O. M. (2001). Anti-inflammatory activites of lactoferrin. J. Am. Coll. Nutr. 20, 389s. doi: 10.1080/07315724.2001.10719173

Enrique, M., Marcos, J. F., Yuste, M., Martinez, M., Valles, S., and Manzanares, P. (2007). Antimicrobial action of synthetic peptides towards wine spoilage yeasts. Int. J. Food Microbiol. 118, 318-325. doi: 10.1016/j.ijfoodmicro.2007.07.049

Farnaud, S., Spiller, C., Moriarty, L. C., Patel, A., Gant, V., Odell, E. W., et al. (2004). Interactions of lactoferricin-derived peptides with LPS and antimicrobial activity. FEMS Microbiol. Lett. 233, 193-199. doi: 10.1111/j.1574-6968.2004.tb09482.x

Feng, X., Liu, C., Guo, J., Song, X., Li, J., Xu, W., et al. (2012). Recombinant expression, purification, and antimicrobial activity of a novel hybrid antimicrobial peptide LFT33. Appl. Microbiol. Biotechnol. 95, 1191-1198. doi: 10.1007/s00253-011-3816-Z

Garcia-Montoya, I. A., Cendon, T. S., Arevalo-Gallegos, S., and Rascon-Cruz, Q. (2012). Lactoferrin a multiple bioactive protein: an overview. BIochi. Biophys. Acta 1820, 226-236. doi: 10.1016/j.bbagen.2011.06.018

Giansanti, F., Leboffe, L., D’Elia, I., and Antonini, G. (2013). An update on the antifungal activities of lactoferrin: new promising applications in diagnostic, therapeutics and biotechnology. Anti Infect. Agents 11, 155-158. doi: 10.2174/2211352511311020009

Gifford, J. L., Hunter, H. N., and Vogel, H. J. (2005). Lactoferricin: a lactoferrinderived peptide with antimicrobial, antiviral, antitumour, and immunological properties. Cell. Mol. Life Sci. 62, 2588-2598. doi: 10.1007/s00018-005-5373-z

González-Chávez, S. A., Arevalo-Gallegos, S., and Rascon-Cruz, Q. (2009). Lactoferrin: structure, function and applications. Int. J. Antimicrob. Agents 33, 301e301-301e308. doi: 10.1016/j.ijantimicag.2008.07.020

Groves, M. L. (1960). The isolation of a red protein from milk. J. Am. Chem. Soc. 82, 3345-3350. doi: 10.1021/ja01498a029

Haney, E. F., Lau, F., and Vogel, H. J. (2007). Solution structures and model membrane interactions of lactoferrampin, an antimicrobial peptide derived from bovine lactoferrin. BIochi. Biophys. Acta 1768, 2355-2364. doi: 10.1016/j.bbamem.2007.04.018

Haney, E. F., Nazmi, K., Lau, F., Bolscher, J. G., and Vogel, H. J. (2009). Novel lactoferrampin antimicrobial peptides derived from human lactoferrin. Biochimie 91, 141-154. doi: 10.1016/j.biochi.2008.04.013

Håversen, L., Kondori, N., Baltzer, L., Hanson, L. A., Dolphin, G. T., Duner, K., et al. (2010). Structure-microbicidal activity relationship of synthetic fragments derived from the antibacterial alpha-helix of human lactoferrin. Antimicrob. Agents Chemother. 54, 418-425. doi: 10.1128/AAC.00908-09

Hunter, H. N., Demcoe, A. R., Jenssen, H., Gutteberg, T. J., and Vogel, H. J. (2005). Human lactoferricin is partially folded in aqueous solution and is better stabilized in a membrane mimetic solvent. Antimicrob. Agents Chemother. 49, 3387-3395. doi: 10.1128/AAC.49.8.3387-3395.2005

Iigo, M., Alexander, D. B., Long, N., Xu, J., Fukamachi, K., Futakuchi, M., et al. (2009). Anticarginogenesis pathways activated by bovine lactoferrin in the murine small intestine. Biochimie 91, 86-101. doi: 10.1016/j.biochi.2008.06.012

Jameson, G. B., Anderson, B. F., Norris, G. E., Thomas, D. H., and Baker, E. N. (1998). Structure of human apolactoferrin at $2.0 \mathrm{~A}$ resolution. Refinement and analysis of ligand-induced conformational change. Acta Crystallogr. D Biol. Crystallogr. 54, 1319-1335. doi: 10.1107/S0907444998004417

Jenssen, H., and Hancock, R. E. (2009). Antimicrobial properties of lactoferrin. Biochimie 91, 19-29. doi: 10.1016/j.biochi.2008.05.015

Kullberg, B. J., Netea, M. G., Vonk, A. G., and Van der Meer, J. W. (1999). Modulation of neutrophil function in host defense against disseminated Candida albicans infection in mice. FEMS Immunol. Med. Microbiol. 26, 299-307. doi: 10.1111/j.1574-695X.1999.tb01402.x

Kirkpatrick, C. H., Green, I., Rich, R. R., and Schade, A. L. (1971). Inhibition of growth of Candida albicans by iron-unsaturated lactoferrin: relation to hostdefence mechanisms in chronic mucocutaneous candidiasis. J. Infect. Dis. 125, 539-544. doi: 10.1093/infdis/124.6.539

Kobayashi, T., Kakeya, H., Miyazaki, T., Izumikawa, K., Yanagihara, K., Ohno, H., et al. (2011). Synergistic antifungal effect of lactoferrin with azole antifungals against Candida albicans and a proposal for a new treatment method for invasive candidiasis. Jpn. J. Infect. Dis. 64, 292-296.

Kondori, N., Baltzer, L., Dolphin, G. T., and Mattsby-Baltzer, I. (2011). Fungicidal activity of human lactoferrin-derived peptides based on the antimicrobial alphabeta region. Int. J. Antimicrob. Agents 37, 51-57. doi: 10.1016/j.ijantimicag.2010.08.020

Kruzel, M. L., Bacsi, A., Choudhury, B., Sur, S., and Boldogh, I. (2006). Lactoferrin decreases pollen antigen-induced allergic airway inflammation in a murine model of asthma. Immunology 119, 159-166. doi: 10.1111/j.1365-2567.2006.02417.x

Kuipers, M. E., de Vries, H. G., Eikelboom, M. C., Meijer, D. K., and Swart, P. J. (1999). Synergistic fungistatic effects of lactoferrin in combination with antifungal drugs against clinical Candida isolates. Antimicrob. Agents Chemother. 43, 2635-2641.

Lahoz, E., Pisacane, A., Iannaccone, M., Palumbo, D., and Capparelli, R. (2008). Fungistatic activity of iron-free bovin lactoferrin against several fungal plant pathogens and antagonists. Nat. Prod. Res. 22, 955-961. doi: 10.1080/14786410701650253

Lai, Y. W., Campbell, L. T., Wilkins, M. R., Pang, C. N., Chen, S., and Carter, D. A. (2016). Synergy and antagonism between iron chelators and antifungal drugs in Cryptococcus. Int. J. Antimicrob. Agents 48, 388-394. doi: 10.1016/j.ijantimicag.2016.06.012

Leboffe, L., Giansanti, F., and Antonini, G. (2009). Antifungal and antiparasitic activites of lactoferrin. Antiinfect. Agents Med. Chem. 8, 114-127. doi: 10.2174/187152109787846105

Liceaga-Gesualdo, A., Li-Chan, E. C., and Skura, B. J. (2001). Antimicrobial effect of lactoferrin digest on spores of a Penicillium sp. isolated from bottled water. Food Res. Int. 34, 501-506. doi: 10.1016/S0963-9969(00) 00180-0

Lönnerdal, B., and Iyer, S. (1995). Lactoferrin: molecular structure and biological function. Annu. Rev. Nutr. 44, 3257-3263. doi: 10.1146/annurev.nu.15.070195.000521

Lupetti, A., Paulusma-Annema, A., Welling, M. M., Dogterom-Ballering, H., Brouwer, C. P., Senesi, S., et al. (2003). Synergistic activity of the N-terminal peptide of human lactoferrin and fluconazole against Candida species. Antimicrob. Agents Chemother. 47, 262-267. doi: 10.1128/AAC.47.1.262-267.2003

Lupetti, A., Paulusma-Annema, A., Welling, M. M., Senesi, S., van Dissel, J. T., and Nibbering, P. H. (2000). Candidacidal activities of human lactoferrin peptides derived from the N terminus. Antimicrob. Agents Chemother. 44, 3257-3263. doi: 10.1128/AAC.44.12.3257-3263.2000

Lupetti, A., van Dissel, J. T., Brouwer, C. P., and Nibbering, P. H. (2008). Human antimicrobial peptides' antifungal activity against Aspergillus fumigatus. Eur. J. Clin. Microbiol. Infect. Dis. 27, 1125-1129. doi: 10.1007/s10096-0080553-Z

Masson, P. L., Heremans, J. F., and Ferin, J. (1968). Presence of an ironbinding protein (lactoferrin) in the genital tract of the human female. I. Its immunohistochemical localization in the endometrium. Fertil. Steril. 19, 679-689. doi: 10.1016/S0015-0282(16)36781-4

Mishra, B., Leishangthem, G. D., Gill, K., Singh, A. K., Das, S., Singh, K., et al. (2013). A novel antimicrobial peptide derived from modified N-terminal domain of bovine lactoferrin: design, synthesis, activity against multidrugresistant bacteria and Candida. Biochim. Biophys. Acta 1828, 677-686. doi: $10.1016 /$ j.bbamem.2012.09.021 
Muñoz, A., and Marcos, J. F. (2006). Activity and mode of action against fungal phytopathogens of bovine lactoferricin-derived peptides. J. Appl. Microbiol. 101, 1199-1207. doi: 10.1111/j.1365-2672.2006.03089.x

Naidu, A. S., Fowler, R. S., Martinez, C., Chen, J., and Tulpinski, J. (2004). Activated lactoferrin and fluconazole synergism against Candida albcians and Candida glabrata vaginal isolates. J. Reprod. Med. 49, 800-807.

Nikawa, H., Samaranayake, L. P., Tenovuo, J., Pang, K. M., and Hamada, T. (1993). The fungicidal effect of human lactoferrin on Candida albicans and Candida krusei. Arch. Oral Biol. 38, 1057-1063. doi: 10.1016/0003-9969(93)90167-K

Ogasawara, Y., Imase, M., Oda, H., Wakabayashi, H., and Ishii, K. (2014). Lactoferrin directly scavenges hydroxyl radicals and undergoes oxidative selfdegradation: a possible role in protection against oxidative DNA damage. Int. J. Mol. Sci. 15, 1003-1013. doi: 10.3390/ijms15011003

Park, J. H., Park, G. T., Cho, I. H., Sim, S. M., Yang, J. M., and Lee, D. Y. (2011). An antimicrobial protein, lactoferrin exists in the sweat: proteomic analysis of sweat. Exp. Dermatol. 20, 369-371. doi: 10.1111/j.1600-0625.2010.01218.x

Sánchez-Gómez, S., Lamata, M., Leiva, J., Blondelle, S. E., Jerala, R., Andra, J., et al. (2008). Comparative analysis of selected methods for the assessment of antimicrobial and membrane-permeabilizing activity: a case study for lactoferricin derived peptides. BMC Microbiol. 8:196. doi: 10.1186/1471-2180-8-196

Silva, T., Adao, R., Nazmi, K., Bolscher, J. G., Funari, S. S., Uhrikova, D., et al. (2013). Structural diversity and mode of action on lipid membranes of three lactoferrin candidacidal peptides. Biochim. Biophys. Acta 1828, 1329-1339. doi: 10.1016/j.bbamem.2013.01.022

Sinha, M., Kaushik, S., Kaur, P., Sharma, S., and Singh, T. P. (2013). Antimicrobial lactoferrin peptides: the hidden players in the protective function of a multifunctional protein. Int. J. Pept. 2013:390230. doi: 10.1155/2013/390230

Sorensen, M., and Sorensen, S. P. L. (1939). The proteins of whey. Compt. Rend. Trav. Lab. Carlsberg Ser. Chim. 23, 35-99.

Ueta, E., Tanida, T., and Osaki, T. (2001). A novel bovine lactoferrin peptide, FKCRRWQWRM, suppresses Candida cell growth and activates neutrophils. J. Pept. Res. 57, 240-249. doi: 10.1111/j.1399-3011.2001.00821.x

van der Does, A. M., Joosten, S. A., Vroomans, E., Bogaards, S. J., van Meijgaarden, K. E., Ottenhoff, T. H., et al. (2012). The antimicrobial peptide hLF1-11 drives monocyte-dendritic cell differentiation toward dendritic cells that promote antifungal responses and enhance Th17 polarization. J. Innate Immun. 4, 284-292. doi: 10.1159/000332941

van der Kraan, M. I., Groenink, J., Nazmi, K., Veerman, E. C., Bolscher, J. G., and Nieuw Amerongen, A. V. (2004). Lactoferrampin: a novel antimicrobial peptide in the N1-domain of bovine lactoferrin. Peptides 25, 177-183. doi: $10.1016 /$ j.peptides.2003.12.006

van der Kraan, M. I., Van der Made, C., Nazmi, K., Van’t Hof, W., Groenink, J., Veerman, E. C., et al. (2005a). Effect of amino acid substitutions on the candidacidal activity of LFampin 265-284. Peptides 26, 2093-2097. doi: 10.1016/j.peptides.2005.03.056

van der Kraan, M. I., Van Marle, J., Nazmi, K., Groenink, J., Van 't Hof, W., Veerman, E. C., et al. (2005b). Ultrastructural effects of antimicrobial peptides from bovine lactoferrin on the membranes of Candida albicans and Escherichia coli. Peptides 26, 1537-1542. doi: 10.1016/j.peptides.2005.02.011 van der Strate, B. W., Belijaars, L., Molema, G., Harmsen, M. C., and Meijer, D. K. (2001). Antiviral activites of lactoferrin. Antiviral Res. 52, 225-239. doi: 10.1016/S0166-3542(01)00195-4

Venkatesh, M. P., and Rong, L. (2008). Human recombinant lactoferrin acts synergistically with antimicrobials commonly used in neonatal practice against coagulase-negative staphylococci and Candida albicans causing neonatal sepsis. J. Med. Microbiol. 57, 1113-1121. doi: 10.1099/jmm.0.2008/001263-0

Viejo-Díaz, M., Andres, M. T., and Fierro, J. F. (2004). Modulation of in vitro fungicidal activity of human lactoferrin against Candida albicans by extracellular cation concentration and target cell metabolic activity. Antimicrob. Agents Chemother. 48, 1242-1248. doi: 10.1128/AAC.48.4.1242-1248.2004

Viejo-Diaz, M., Andres, M. T., and Fierro, J. F. (2005). Different antiCandida activities of two human lactoferrin-derived peptides, Lfpep and Kaliocin-1. Antimicrob. Agents Chemother. 49, 2583-2588. doi: 10.1128/AAC.49.7.2583-2588.2005

Wakabayashi, H., Abe, S., Okutomi, T., Tansho, S., Kawase, K., and Yamaguchi, H. (1996). Cooperative anti-Candida effects of lactoferrin or its peptides in combination with azole antifungal agents. Microbiol. Immunol. 40, 821-825. doi: 10.1111/j.1348-0421.1996.tb01147.x

Wakabayashi, H., Abe, S., Teraguchi, S., Hayasawa, H., and Yamaguchi, H. (1998). Inhibition of hyphal growth of azole-resistant strains of Candida albicans by triazole antifungal agents in the presence of lactoferrin-related compounds. Antimicrob. Agents Chemother. 42, 1587-1591.

Wakabayashi, H., Matsumoto, H., Hashimoto, K., Teraguchi, S., Takase, M., and Hayasawa, H. (1999). N-acylated and D enantiomer derivatives of a nonamer core peptide of lactoferricin B showing improved antimicrobial activity. Antimicrob. Agents Chemother. 43, 1267-1269.

Xu, Y., Wang, Y., Yan, L., Liang, R. M., Dai, B. D., Tang, R. J., et al. (2009). Proteomic analysis reveals a synergistic mechanism of fluconazole and berberine against fluconazole-resistant Candida albicans: endogenous ROS augmentation. J. Proteome Res. 8, 5296-5304. doi: 10.1021/pr9005074

Xu, Y. Y., Samaranayake, Y. H., Samaranayake, L. P., and Nikawa, H. (1998). In vitro susceptibility of Candida species to lactoferrin. Med. Mycol. 37, 35-41. doi: 10.1080/02681219980000051

Zarember, K. A., Sugui, J. A., Chang, Y. C., Kwon-Chung, K. J., and Gallin, J. I. (2007). Human polymorphonuclear leukocytes inhibit Aspergillus fumigatus conidial growth by lactoferrin-mediated iron depletion. J. Immunol. 178, 6367-6373. doi: 10.4049/jimmunol.178.10.6367

Conflict of Interest Statement: The authors declare that the research was conducted in the absence of any commercial or financial relationships that could be construed as a potential conflict of interest.

Copyright (c) 2017 Fernandes and Carter. This is an open-access article distributed under the terms of the Creative Commons Attribution License (CC BY). The use, distribution or reproduction in other forums is permitted, provided the original author(s) or licensor are credited and that the original publication in this journal is cited, in accordance with accepted academic practice. No use, distribution or reproduction is permitted which does not comply with these terms. 